\title{
Medical Complications in Lung Transplant Recipients with Pulmonary Fibrosis
}

\author{
Kamyar Afshar*, Ngozi Orjioke, and Timothy Whelan \\ Division of Pulmonary and Critical Care, University of Southern California, Keck School of Medicine, USA
}

\begin{abstract}
Lung transplantation is a therapeutic option for selected patients with severe interstitial disease who continue to have progressive clinical deterioration. There is a survival advantage for selected patients who undergo transplant, but it primarily improves quality of life after transplantation. Unfortunately, patients with IPF have worse outcomes following lung transplantation due to various factors. This review article will describe several common postoperative complications including an astamotic complications, allograft dysfunction, cardiovascular complications, thromboembolic phenomenon, renal failure, neurologic complications and complications related to the native lung in the single lung transplant recipients.
\end{abstract}

Keywords: Lung transplantation; Pulmonary fibrosis; Complications

\section{Introduction}

To date, all the medical therapies evaluated for patients with Idiopathic Pulmonary Fibrosis (IPF) have had no effect on the natural course of the disease. Lung transplantation is a therapeutic option for selected patients with severe interstitial disease who continue to have progressive clinical deterioration. Through June 30, 2011, there have been 39,835 lung transplants performed worldwide [1]. Worldwide, pulmonary fibrosis is the second most common indication for lung transplantation. Unfortunately, the 5-year survival for patients with IPF is the lowest compared to patients with other lung ailments requiring lung transplantation (Chart 1).

As more patients are being transplanted and living a significant distance from the transplant center, more physicians without specific training in transplantation are encountering visits by these patients. To ensure appropriate and timely care for lung transplant recipients, there needs to be increased awareness of common potential complications after lung transplantation. This review article will describe several common post-operative complications that may arise.

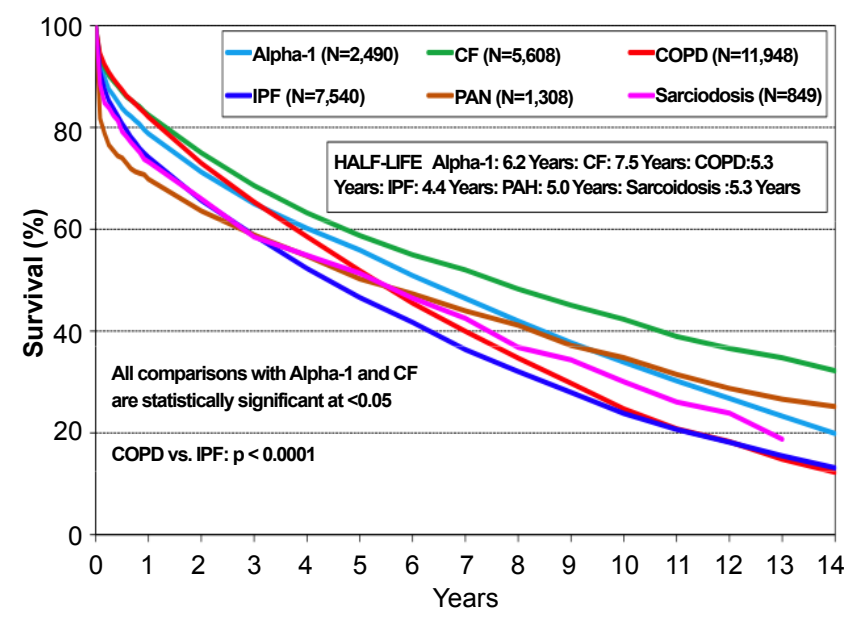

Chart 1: Kaplan-Meier survival by diagnosis for adult lung transplants performed between January 1990 and June 2010. Alpha-1, $\alpha 1$-antitrypsin deficiency emphysema; CF, cystic fi- brosis; COPD, chronic obstructive pulmonary disease; IPF, idiopathic pulmonary fibrosis; $\mathrm{PAH}$, pulmonary arterial hypertension [Christie JD, Edwards LB, Kucheryavaya AY, et al. The registry of the international society for heart and lung transplantation: 29th adult lung and heart-ling transplantation report - 2012. J Heart Lung Transplant 2012;31:10731086].

\section{Types of Transplant Procedures}

Any of four surgical options are available to patients needing lung transplantation; Single Lung Transplant (SLT), Bilateral Sequential Lung Transplant (BSLT), Living Lobar Transplant and Heart-Lung Transplant (HLT). Since the mid 1990s, the number of BSLT has consistently increased for all the major underlying disease categories. This is equally true for recipients with pulmonary fibrosis; rates rose from $20 \%$ in 1998 to $50 \%$ in 2010 .

When viewing the survival rates according to procedure type, BSLT appears to be better than SLT. These survival differences may be influenced by clinical factors such as age, underlying lung disorder, experience of lung transplant center, recipient co-morbidities and characteristics of procured donor allograft [1]. The survival advantage may be more apparent in the in the later years of lung transplantation. The peri-operative mortality has been shown to be higher in the BSLT recipients; 1 -month mortality $21 \%$ for BSLT versus $10 \%$ for SLT [2]. Conditional half-lives (patients surviving at least 1year) are 9.4 years for BSLT versus 6.5 years for SLT. Short-term and long-term survival rates are also significantly related to recipient age. Patients less than 50 years of age have a 1-year survival of $80 \%$ compared to $72 \%$ in patients greater than 65 and a 5 -year survival of 56\% compared to $37 \%$ respectively.

Survival comparisons within diagnoses are the lowest in the COPD and IPF groups (6.8 years) compared to other diagnoses (CF 10.4 years; PAH 10.0 years; sarcoidosis 8.6 years; alpha- 1 antitrypsin deficiency 8.6 years). Survival did not differ between procedure types in patients with idiopathic pulmonary fibrosis [3]. Improvements in lung respiratory mechanics and an enhanced pulmonary reserve have been proposed reasons for the survival advantage in recipients with BSLT [4]. Lung function assessments; however, are similar between BSLT and SLT recipients. The mean vital capacity before transplantation is approximately $40-45 \%$ of predicted. This value increases to $65 \%$ within

*Corresponding author: Kamyar Afshar, Assistant Professor of Clinical Medicine University of Southern California, Keck School of Medicine, Division of Pulmonary and Critical Care, 2020 Zonal Ave, IRD 723, Los Angeles, CA 90033, Tel: 323-226-7923; Fax: 323-226-2873; E-mail: kafshar@usc.edu

Received February 14, 2013; Accepted April 02, 2013; Published April 05, 2013

Citation: Afshar K, Orjioke N, Whelan T (2013) Medical Complications in Lung Transplant Recipients with Pulmonary Fibrosis. J Pulmon Resp Med 3: 145 doi:10.4172/2161-105X. 1000145

Copyright: @ 2013 Afshar K, et al. This is an open-access article distributed under the terms of the Creative Commons Attribution License, which permits unrestricted use, distribution, and reproduction in any medium, provided the original author and source are credited. 
3 months following single lung transplantation [5]. Improvements in the lung functions continue for up to one year. On the first anniversary, mean forced expiratory volume in one second $\left(\mathrm{FEV}_{1}\right)$ is approximately $2.00 \mathrm{~L}$ in SLT recipients compared to 2.25 L in BSLT recipients [6].

\section{Immunosuppression Therapy}

Acute rejection rates are extremely common in the first year after lung transplantation with approximately $30-40 \%$ of recipients having at least one episode in the first year after transplant [1]. Standard triple drug immunosuppressive agents are prescribed to minimize this risk. Appropriate dosing must balance the benefits of preventing rejection with the risk of infection. The regimen typically includes prednisone, an antimetabolite (azathioprine or mycophenolate mofetil) and a calcineurin inhibitor (tacrolimus or cyclosporine). Although these medications have unique side effects, the cumulative dose or degree of immunosuppression predisposes individuals to opportunistic infections, malignancies, renal failure, post-transplant diabetes mellitus, hypertension and dyslipidemia. Table 1 reviews common drug interactions that can alter clearance or therapeutic drug levels.

\section{Allograft Parenchymal Abnormalities}

The lung allograft is subject to a variety of insults resulting in various parnechymal abnormalities. They are broadly classified as infectious and non-infectious in etiology. Infections are the leading cause of morbidity and mortality in the first three years of transplantation [1]. Bacterial pathogens are predominantly implicated, but fungal and viral infections, are also of great concern (particularly Aspergillus and cytomegalovirus).

Unfortunately, radiographic pulmonary parenchymal abnormalities can be nonspecific (Figure 1). Bacterial and fungal infections can be difficult to discern as radiographic features can include consolidation, ill-defined nodules, and cavitation and ground glass opacifications. Viral infections, particularly CMV, may have normal radiographs or show ground-glass attenuation, micronodules, reticulonodular opacities, and/or consolidation. To confound the diagnostic challenges, radiographic features of Acute Cellular Rejection (ACR) can present similar to any of the previously mentioned complications. ACR radiographic features can appear as normal radiograph, ground-glass opacities, consolidation, nodules, alveolar opacities, a new exudative or increasing size of pleural effusion (seen in $43 \%$ of patients) $[7,8]$.

As a result of the lack of specificity of imaging studies, broad-

\begin{tabular}{|l|l|}
\hline Immunosuppressant Agent & Drug Interactions \\
\hline Calcineurin inhibitors: & $\begin{array}{l}\text { Increased CNI levels: } \\
\text { allopurinol, azole antifungals, calcium channel } \\
\text { blockers, colchicines, lansoprazole, macrolides, } \\
\text { rabeprazole } \\
\text { Decreased CNI levels: } \\
\text { Barbiturates carbamazepine, eiconacandins } \\
\text { phenytoin, rifampin, rifabutin, } \\
\text { St. John's wort, ticlopidine }\end{array}$ \\
\hline Azathioprine & $\begin{array}{l}\text { allopurinol and ACE inhibitors slow azathioprine } \\
\text { elimination thereby causing bone marrow } \\
\text { suppression peak }\end{array}$ \\
\hline Mycophenolate mofetil & $\begin{array}{l}\text { proton pump inhibitors reduce MPA pen } \\
\text { concentrations } \\
\text { norfloxacin \& metronidazole combination reduce } \\
\text { MPA trough concentrations } \\
\text { rifampin reduces MPA exposure }\end{array}$ \\
\hline
\end{tabular}

Table 1: Common drug-drug interactions with immunosuppressants: The alteration of therapeutic drug levels or clearance of immunosuppressants

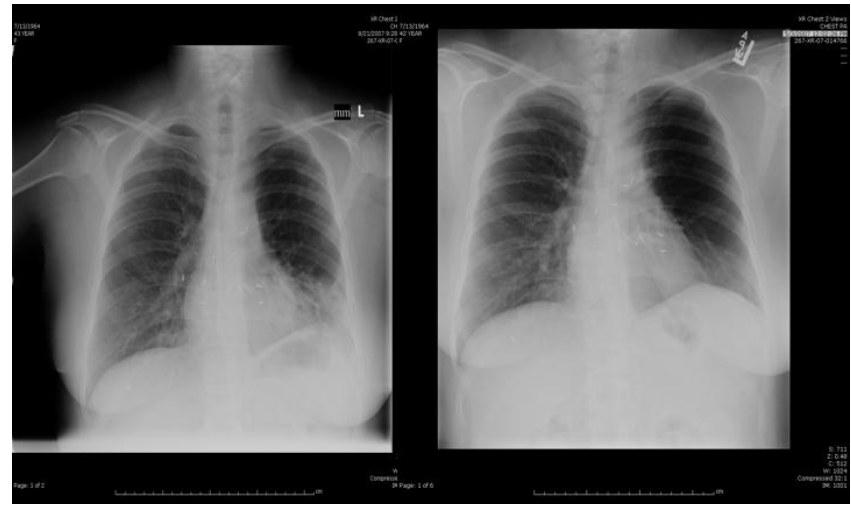

Figure 1: 43 year old female with bilateral sequential lung transplant for IPF presents with persistent fever, chills and productive sputum despite oral antibiotics. Chest radiograph (left) indicates a new left lower lobe opacity/ air space disease. Chest radiograph 6 weeks earlier (right) is viewed for comparison. Transbronchial biopsy revealed the presence of ISHLT grade A1 acute cellular rejection.

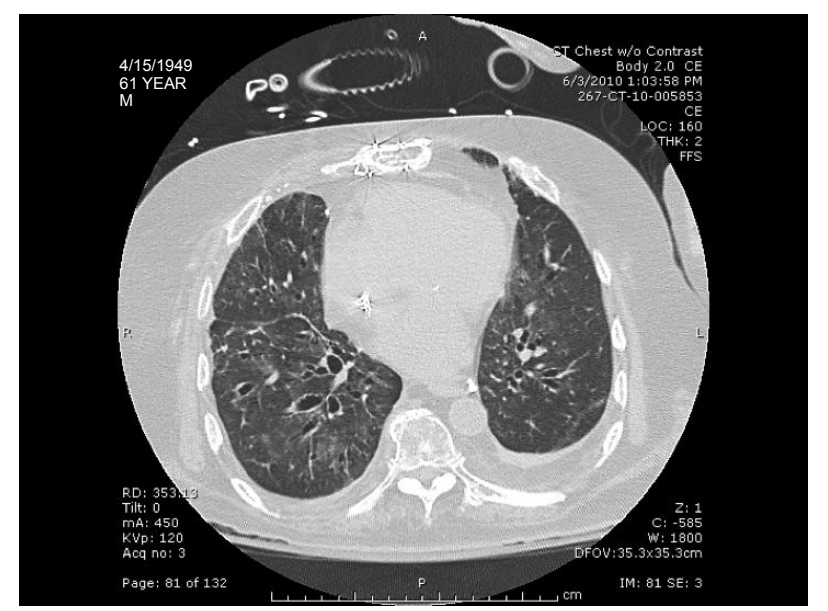

Figure 2: 61 year old male two years after bilateral sequential lung transplant for AIP developing BOS. Features include bronchiectasis in the bilateral lower lobes and right middle lobe, which is predominantly cylindrical but also varicose and saccular in the right lower lobe.

spectrum antimicrobial therapy is often instituted in the acutely ill lung transplant recipient. One must maintain a broad infectious disease differential given the triple drug immunosuppression when considering treatment options. Additionally, as acute rejection is on the differential, obtaining a definitive diagnosis is mandatory. Clinical correlation and transbronchial biopsy is generally indicated for obtaining the diagnosis. Infections and number of acute cellular rejections contribute to a higher risk of developing chronic rejection.

Primary Graft Dysfunction (PGD) accounts for the main cause of death within the first 30 days following lung transplantation (1). The underlying diagnosis of fibrotic disease is not predictive of developing PGD (restrictive disease with PGD 22.1\% versus without PGD 20.3\%) [9]. More recently, it has been demonstrated that patients with IPF and associated pulmonary hypertension have a higher incidence of developing PGD [10]. They found a 1.64 increase in the odds of developing the severe form PGD (grade 3) for each $10 \mathrm{mmHg}$ increase in the mean pulmonary artery pressure.

Prompt diagnosis and therapy may contribute to a lower incidence of chronic allograft rejection. Chronic allograft rejection has been observed 
as Bronchiolitis Obliterans Syndrome (BOS) or Restrictive Allograft Syndrome (RAS). BOS usually presents as progressive airflow limitation noted on Pulmonary Function Testing (PFT). Patients are classified into different grades depending on the severity of airflow limitation relative to their best post-transplant $\mathrm{FEV}_{1}$. Typical radiographic appearances include a mixture of hypo- and hyperattenuation (mosaic attenuation) regions produced by air trapping and decreased peripheral vascularity, subsegmental atelectasis and bronchiectasis (Figure 2) [8]. Features of RAS include upper lobe fibrosis. Radiographic features include reticulonodular opacities, traction bronchiectasis, honeycombing, interlobular septal thickening and loss of lung volume (Figure 3). Unlike the obstructive airflow limitation previously described, these patients have restrictive physiology on PFTs $[8,11]$.

The presence of BAL eosinophilia and neutrophilia, airway infection colonization and acute cellular/lymphocytic bronchiolitis episodes are risk factors to develop both BOS and RAS [12]. The underlying disease or ILD does not appear to influence the development of one form of chronic allograft rejection (24\% BOS and 20.8\% RAS).

Augmenting immunosupression or altering medications within therapeutic classes has been advocated when patients develop chronic rejection. There is clearly a small subset of patients who may respond to this therapy, however, it does increase the risk of reemerging opportunistic infections and development of malignant processes. This must be carefully considered when pursuing this approach to treatment of chronic rejection with increased immunosuppression. One alternative therapy for BOS that is becoming more routinely used is chronic azithromycin treatment. Several small series as well as one prospective, randomized, double blind, placebo-controlled trial have suggested a potential benefit for the use of azithromycin in lung transplant recipients [13-15]. This benefit is for both the prevention of development of BOS, as well as successful treatment for a subset of patients who have already developed BOS. Although the mechanism for the positive effect of azithromycin is not well elucidated, it is believed that the drug's anti-inflammatory properties are likely the cause. Chronic azithromycin therapy appears to be well tolerated although there is an increased risk of gastrointestinal side effects, QTc prolongation and auditory distrubances. In addition, the potential effects of antimicrobial selection are not well understood. Clinicians should be aware that this medication is often taken chronically and ensure this is considered when choosing antibiotics for an acute respiratory infection.

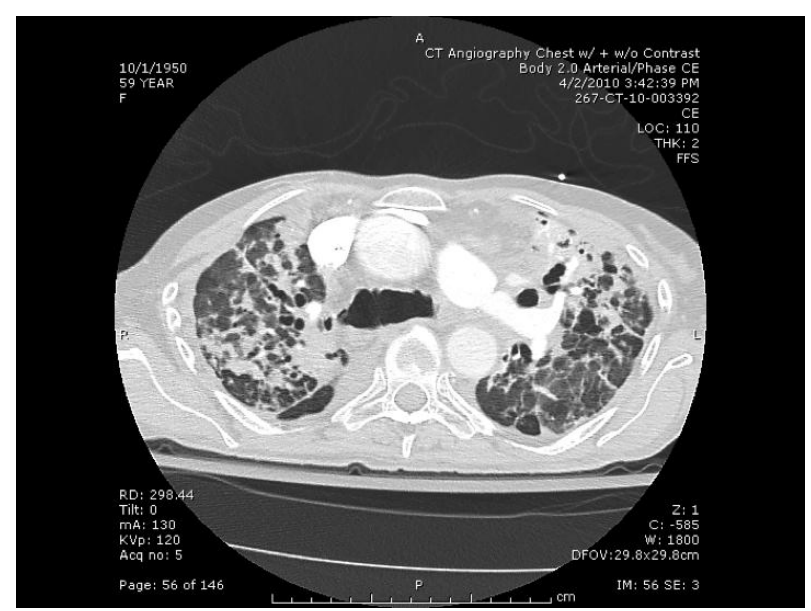

Figure 3: 59 year old female five years after bilateral sequential lung transplant for IPF with fibrotic BOS.

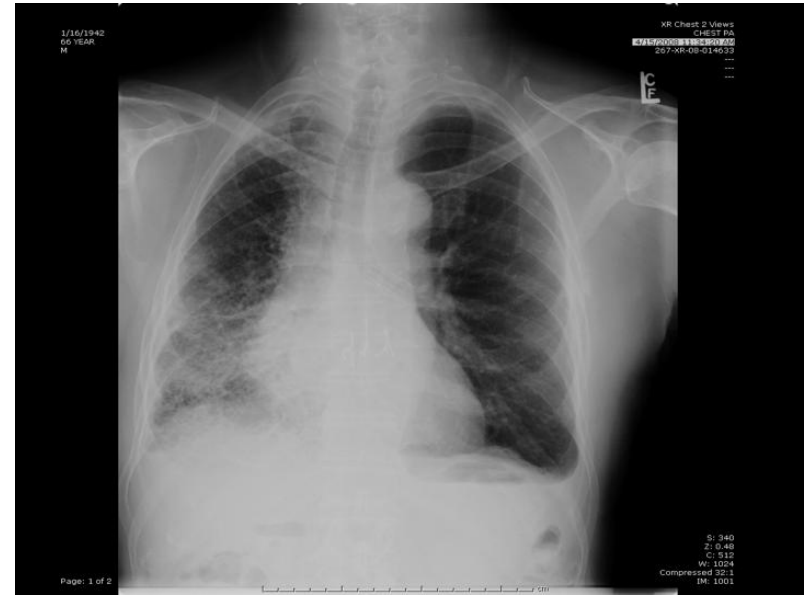

Figure 4: 66 year old male with a left single lung transplant for IPF with airway stricture requiring a self expandable metallic stent (SEMS) in left anastamotic site

\section{Anastamotic Complications}

\section{Airway}

Currently, the bronchial anastamosis is created in an "end-to-end" fashion without an omental wrap. Bronchial artery circulation is lost during the harvesting and not routinely reestablished in the implantation process making the donor bronchus and anastamosis dependent solely on the poorly oxygenated pulmonary artery rendering the area to be ischemic. Early complications ( $<3$ months) from ischemia include necrosis and wound dehiscence. During the healing and remodeling phase, typical complications are airway stenosis, granulation tissue formation and malacia which can occur later (> 3months). Graft rejection, immunosuppression, and bronchopulmonary infections, particularly bacterial and fungal organisms, have also been associated with airway complications. These lung transplant related airway complications occur in up to $30 \%$ of patients [16,17]. Management strategies include laser photoresection, cryoablation, airway dilation and silicone or self-expandable metallic stents. The stents are generally placed when respiratory symptoms ensue and are refractory to the other mentioned modalities (Figure 4). Although most patients benefit with improvement in symptomology and lung functions, complications can arise from this therapeutic intervention as well. Mucus plugging, obstructive granuloma, fracture of the stent, migration and infectious colonizations are routinely assessed.

\section{Vasculature}

Vascular anastamotic complications are relatively uncommon, but have a high morbidity and mortality associated with it. Pulmonary arterial stenosis is more common, whereas stenosis at the atrial cuff and pulmonary vein are rare. When it occurs, this complication is generally early following transplantation [18]. Symptoms include dyspnea, cough, increasing oxygen requirement, persistent elevation in pulmonary artery pressures and pulmonary edema. We present a case of a 67 year-old man who developed dyspnea, hypoxemia and hypercapnea 3 months following a single lung transplant for IPF. Investigations indicated a pulmonary artery stenosis (Figure 5).

Potential contributing factors for the development of pulmonary artery stenosis includes small chest wall size, small recipient artery and difficulty accessing the vessel thereby causing stenosis or kinking of the vessel and the anastamotic site. Diagnostic strategies include utilization of a quantitative perfusion scan, CT pulmonary angiogram 


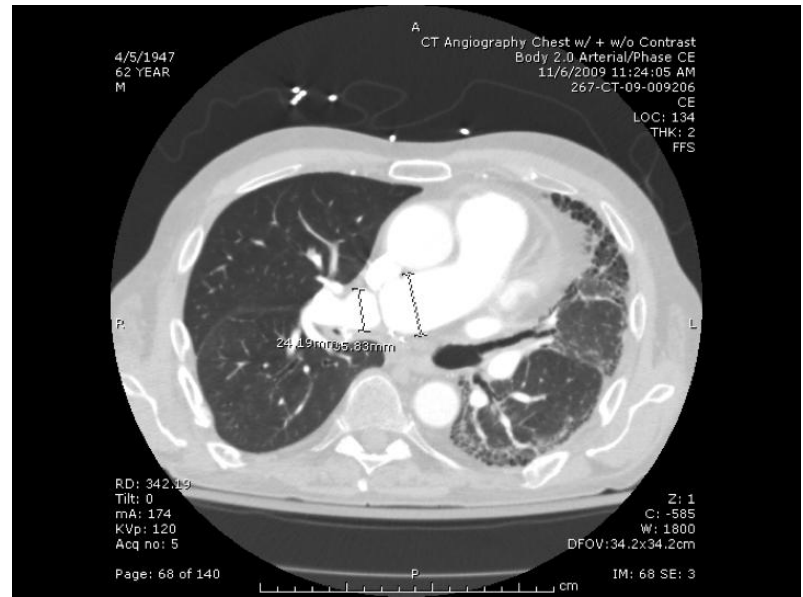

Figure 5: 62 year old male 3 months following a right single lung transplant for IPF developed dyspnea and hypoxemia. CT angiogram of the chest found focal web-like or shelf-like stenosis in the right pulmonary artery at the level of the anastomosis. The pre-stenotic segment measured $3.1 \times 2.9 \mathrm{~cm}$. At the level of stenosis the lumen narrowed to $1.1 \times 1.0 \mathrm{~cm}$. Distal to the stenosis, the artery measured $2.6 \times 2.2 \mathrm{~cm}$

and/or transesophageal echocardiography. Treatment options include observation, re-operation or angiography with or without stent deployment.

\section{Complications of Native Lung Disease in Single Lung Transplant Recipients}

Clinicians should be mindful that patients' native lung disease progression is not halted with the contralateral lung transplantation despite triple drug immunosuppression. Recipients are still at risk for progression of disease and related complications arising from the native lung. The average percentage of native lung ground glass opacification or fibrosis remains unchanged or increases for the majority of single lung transplant recipients with IPF [19]. Annually, IPF patients are noted to lose $10.8 \%$ of native lung volume and an $11 \%$ increase in fibrosis for the first four years following SLT [20]. At the time of transplantation, $52 \%$ of the native lung had evidence of fibrosis, compared to $92 \%$ at four years.

Typical complications reported in IPF patients include bacterial or fungal bronchopulmonary infections, pneumothoraces, retention of secretions causing bronchial obstruction and atelectasis [21]. In addition, acute exacerbation of IPF is being increasingly recognized. This is an abrupt worsening of underlying lung disease potentially evoked by a pneumothorax, pulmonary infection or embolism [22]. Bronchogenic carcinomas have been reported at higher rates in single lung transplant recipients. Significant contributing risk factors include advanced recipient or donor age, smoking history ( $>60$ pack years), and COPD or IPF as the underlying lung disease [23].

\section{Cardiovascular Complications}

During lung transplantation, a cuff of the donor atrial cuff surrounding the pulmonary veins is sewn into the recipient atrium. This incision should technically block (ablate) electrical conduction between the pulmonary artery and atrium and reduce the risks of supraventricular tachcardias (atrial flutter and fibrillation). Nonetheless, $20-46 \%$ of lung transplant recipient develop post-operative atrial arrhythmias primarily on the second to fourth post-operative day, but can develop up to six weeks following surgery [24,25]. Significant risk factors include prior history of coronary artery disease with greater than $50 \%$ vessel stenosis, number of post-operative vasopressors and inotropes, age greater than 50 years, presence of an enlarged left atrium, undergoing concurrent Coronary Artery Bypass Graft (CABG), having a high sympathetic tone, and being diagnosed with IPF as the underlying lung disease (55.9\%). The higher atrial arrhythmias prevalence in IPF patients may be related to older recipient age (age-related structural heart disease) and a more technically challenging operation (underlying parenchymal fibrosis and adhesions) [24].

The general approach to treatment is similar to patients in the general population as they have risks for hemodynamic instability, embolic cerebral vascular accidents and increased mortality. It is imperative to restore normal sinus rhythm after lung transplantation. Patients poorly tolerate the consequences of shortened chamber filling, particularly lung allograft congestion. Treating these arrhythmias can be challenging. Combination pharmacological therapy has been required to restore normal sinus rhythm. Beta-blockers, amiodarone or calcium channel blockers are the drugs of choice. Approximately one-third of patients may require electrical cardioversion. Calcium channel blockers should be used judiciously with an understanding of the potential drug/ drug interaction with calcineurin inhibitors and ensure appropriate drug levels are maintained. Although pharmacological agents can easily control the rate or rhythm, the clinical outcome for patients with atrial arrhythmia are worse compared to those without it. Patients with atrial arrhythmias have a higher likelihood of hospitalization and overall survival is decreased. The 1-year survival for patient without atrial fibrillation is reported to be $90 \%$ compared to $70 \%$ [24].

\section{Thromboembolic Disease}

The incidence of Deep Vein Thrombus (DVT) and Pulmonary Emboli (PE) in the lung transplant population occurs in up to $29 \%$ of recipients. Of these events, almost two-thirds will develop in the first year of transplantation with $20 \%$ of these occurring within the first month. Clearly, reduced mobility from functional limitations and recent surgery are risk factors; however, we also know that inflammation inhibits anticoagulant factors $[26,27]$. Other risk factors include increased age, episodes of pneumonia, male gender, diabetes mellitus, utilization of cardiopulmonary bypass and, in particular, an underlying disease of IPF [28-30]. Most of the pulmonary emboli occur within the allograft (86\%) [29,31].

Postulated mechanisms include the thrombogenic surface of the vasculature anastamosis and increased perfusion to the allograft, along with a lower pulmonary vascular resistance in single lung transplant recipients. The native lung, however, is still not exempt from developing a PE [29]. The median time of developing PEs are 5.8 months following lung transplantation. Some centers advocate prophylactic anticoagulation for up to 6-9 months. Fortunately, the majority of patients tolerate an embolic event from the hemodynamic parameters even in the presence of large clot burden. In addition, the clot burden has not translated into any loss of lung allograft functions [32].

\section{Renal Failure}

A quarter to half of all lung transplant recipients develop some degree of renal dysfunction within the first year of transplantation $[1,33]$. Patients predominantly develop chronic kidney disease stage III (glomerular filtration rate $30-59 \mathrm{cc} / \mathrm{min}$ ). The accumulation of druginduced nephrotoxicity (calcineurin-inhibitors and anti-viral agents), hypertension, diabetes mellitus and dyslipidemia are common etiologic factors. Early post-operative insults will also increase the likelihood of chronic renal failure. Such factors include; hypotension, hemodynamic 
shifts, reduced kidney perfusion and the aggressive use of diuretics. The development of chronic kidney disease leads to a four to five-fold increase risk of death [34]. Older recipient age (greater than 50 years) predicted a shorter period to the development of renal dysfunction [33].

Management strategies to reduce the risk of renal failure include optimizing blood pressure control, dyslipidemia, and diabetes mellitus. Other challenges include the individual tailoring of administration of antiviral agents and balancing the calcineurin inhibitor therapeutic drug levels between renal failure and risks of allograft rejection. On occasion mTOR inhibitors (eg. sirulimus) have been used to reduce calcineurin inhibitor levels or adjuct therapy as a "calcineurin inhibitor sparing" agent [35]. Less than $3 \%$ of patients will have progressive renal failure to the point where hemodialysis is required. Considerations are also taken into account for kidney transplantation, but only $0.5 \%$ of all patients with renal failure ever receive it [1].

\section{Neurologic Complications}

Lung transplants recipients are at risk of developing some form of neurologic complications, such as encephalopathy, headaches, tremors, peripheral neuropathy or critical care myopathy, central nervous system infections, seizures and cerebrovascular accidents [36,37]. Hyperammonia has also been recently linked to etiology of patient confusion $[38,39]$. Interestingly, this complication may not be a drug class effect. Some individuals experience these signs and symptoms with tacrolimis, but resolve while on therapeutic dose of cyclosporin and vice versa.

Recipients appear to be most susceptible in the first year following transplantation. The majority of these complications have been primarily linked to the adverse events related to older recipient age, undergoing BLST, Calicneurin Inhibitors (CNI), tacrolimus and cyclosporine, or infections. The median recipient age was 50.8 years in 2008 with substantial increased number of transplants being performed in patients over the age of 60 [1]. Although the underlying lung disease could not predict the development of neurological complication, IPF patients are generally older and should be closely monitored. Diagnostic work-up is similar to the general population. When reviewing brain MRI and CT scans, it should be known that bilateral white matter abnormalities (leukoencephalopathy) in the posterior region have been noted and associated with calcineurin inhibitor neurotoxicity [40].

\section{Conclusion}

Lung transplantation is a viable therapeutic option for patients with pulmonary fibrosis who are refractory to medical therapy. Although the worldwide cumulative survival rates are improving with more recent eras of practice, pulmonary fibrosis patients continue to have the worst survival following lung transplantation. Despite this, there is a survival advantage for selected patients who undergo transplant $[41,42]$. In addition, quality of life improves after transplantation. The ISHLT registry data shows lung transplant recipients have better general health, quality of life and return to work. $30 \%$ of patients are working either part-time or full-time at 1 -year with this measure increasing to $50 \%$ at 5 years. Multiple other investigators have consistently demonstrated improvements in several aspects of quality of life as well [43-46].

Lung transplantation is not benign however. Transplant recipients are fully informed of significant risks for various complications as outlined within the text. All measures should be taken to reduce risk factors before and after the procedure that can potentially improve longterm outcomes. As more lung transplant recipients receive treatment by physicians outside the transplant institutions, an increased awareness of all the considerations is imperative for these patients.

\section{References}

1. Christie JD, Edwards LB, Kucheryavaya AY, Benden C, Dipchand Al, et al. (2012) The Registry of the International Society for Heart and Lung Transplantation: 29th adult lung and heart-lung transplant report-2012. J Heart Lung Transplant 31: 1073-1086.

2. Meyer DM, Edwards LB, Torres F, Jessen ME, Novick RJ (2005) Impact of recipient age and procedure type on survival after lung transplantation for pulmonary fibrosis. Ann Thorac Surg 79: 950-957.

3. Thabut G, Christie JD, Ravaud P, Castier Y, Dauriat G, et al. (2009) Survival after bilateral versus single-lung transplantation for idiopathic pulmonary fibrosis. Ann Intern Med 151: 767-774.

4. Mason DP, Brizzio ME, Alster JM, McNeill AM, Murthy SC, et al. (2007) Lung transplantation for idiopathic pulmonary fibrosis. Ann Thorac Surg 84: 1121 1128.

5. Miyoshi S, Schaefers HJ, Trulock EP, Yamazaki F, Schreinemakers H, et al (1990) Donor selection for single and double lung transplantation. Chest size matching and other factors influencing posttransplantation vital capacity. Chest 98: 308-313.

6. Meyers BF, Lynch JP, Trulock EP, Guthrie T, Cooper JD, et al. (2000) Single versus bilateral lung transplantation for idiopathic pulmonary fibrosis: a tenyear institutional experience. J Thorac Cardiovasc Surg 120: 99-107.

7. Loubeyre P, Revel D, Delignette A, Loire R, Mornex JF (1995) High-resolution computed tomographic findings associated with histologically diagnosed acute lung rejection in heart-lung transplant recipients. Chest 107: 132-138.

8. Krishnam MS, Suh RD, Tomasian A, Goldin JG, Lai C, et al. (2007) Postoperative complications of lung transplantation: radiologic findings along a time continuum. Radiographics 27: 957-974.

9. Thabut G, Vinatier I, Stern JB, Lesèche G, Loirat P, et al. (2002) Primary graft failure following lung transplantation: predictive factors of mortality. Chest 121 : 1876-1882.

10. Fang A, Studer S, Kawut SM, Ahya VN, Lee J, et al. (2011) Elevated pulmonary artery pressure is a risk factor for primary graft dysfunction following lung transplantation for idiopathic pulmonary fibrosis. Chest 139: 782-787.

11. Pakhale SS, Hadjiliadis D, Howell DN, Palmer SM, Gutierrez C, et al. (2005) Upper lobe fibrosis: a novel manifestation of chronic allograft dysfunction in lung transplantation. J Heart Lung Transplant 24: 1260-1268.

12. Verleden SE, Ruttens D, Vandermeulen E, Vaneylen A, Dupont LJ, et al. (2013) Bronchiolitis Obliterans Syndrome and Restrictive Allograft Syndrome: Do Risk Factors Differ? Transplantation .

13. Gerhardt SG, McDyer JF, Girgis RE, Conte JV, Yang SC, et al. (2003) Maintenance azithromycin therapy for bronchiolitis obliterans syndrome results of a pilot study. Am J Respir Crit Care Med 168: 121-125.

14. Kanazawa S, Nomura S, Muramatsu M, Yamaguchi K, Fukuhara S (2004) Azithromycin and bronchiolitis obliterans. Am J Respir Crit Care Med 169: 654-655.

15. Verleden GM, Dupont LJ (2004) Azithromycin therapy for patients with bronchiolitis obliterans syndrome after lung transplantation. Transplantation 77 1465-1467.

16. Santacruz JF, Mehta AC (2009) Airway complications and management after lung transplantation: ischemia, dehiscence, and stenosis. Proc Am Thorac Soc 6: 79-93.

17. Dutau H, Cavailles A, Sakr L, Badier M, Gaubert JY, et al. (2010) A retrospective study of silicone stent placement for management of anastomotic airway complications in lung transplant recipients: short- and long-term outcomes. J Heart Lung Transplant 29: 658-664.

18. Clark SC, Levine AJ, Hasan A, Hilton CJ, Forty J, et al. (1996) Vascular complications of lung transplantation. Ann Thorac Surg 61: 1079-1082.

19. Wahidi MM, Ravenel J, Palmer SM, McAdams HP (2002) Progression of idiopathic pulmonary fibrosis in native lungs after single lung transplantation. Chest 121: 2072-2076

20. Elicker BM, Golden JA, Ordovas KG, Leard L, Golden TR, et al. (2010) Progression of native lung fibrosis in lung transplant recipients with idiopathic pulmonary fibrosis. Respir Med 104: 426-433. 
Citation: Afshar K, Orjioke N, Whelan T (2013) Medical Complications in Lung Transplant Recipients with Pulmonary Fibrosis. J Pulmon Resp Med 3: 145. doi:10.4172/2161-105X. 1000145

21. Frost AE, Keller CA, Noon GP, Short HD, Cagle PT (1995) Outcome of the native lung after single lung transplant. Multiorgan Transplant Group. Chest 107: 981-984.

22. Kim DS, Collard HR, King TE Jr (2006) Classification and natural history of the idiopathic interstitial pneumonias. Proc Am Thorac Soc 3: 285-292.

23. Mathew J, Kratzke RA (2009) Lung cancer and lung transplantation: a review. J Thorac Oncol 4: 753-760.

24. Nielsen TD, Bahnson T, Davis RD, Palmer SM (2004) Atrial fibrillation after pulmonary transplant. Chest 126: 496-500.

25. Mason DP, Marsh DH, Alster JM, Murthy SC, McNeill AM, et al. (2007) Atria fibrillation after lung transplantation: timing, risk factors, and treatment. Ann Thorac Surg 84: 1878-1884.

26. Grignani G, Maiolo A (2000) Cytokines and hemostasis. Haematologica 85 967-972.

27. Esmon CT (2005) The interactions between inflammation and coagulation. $\mathrm{Br}$ J Haematol 131: 417-430.

28. Yegen HA, Lederer DJ, Barr RG, Wilt JS, Fang Y, et al. (2007) Risk factors for venous thromboembolism after lung transplantation. Chest 132: 547-553.

29. Nathan SD, Barnett SD, Urban BA, Nowalk C, Moran BR, et al. (2003) Pulmonary embolism in idiopathic pulmonary fibrosis transplant recipients. Chest 123: 1758-1763.

30. Kahan ES, Petersen G, Gaughan JP, Criner GJ (2007) High incidence of venous thromboembolic events in lung transplant recipients. J Heart Lung Transplant 26: 339-344.

31. Burns KE, lacono AT (2004) Pulmonary embolism on postmortem examination: an under-recognized complication in lung-transplant recipients? Transplantation 77: 692-698.

32. Kroshus TJ, Kshettry VR, Hertz MI, Bolman RM 3rd (1995) Deep venous thrombosis and pulmonary embolism after lung transplantation. J Thorac Cardiovasc Surg 110: 540-544.

33. Canales M, Youssef P, Spong R, Ishani A, Savik K, et al. (2006) Predictors of chronic kidney disease in long-term survivors of lung and heart-lung transplantation. Am J Transplant 6: 2157-2163.

34. Ojo AO, Held PJ, Port FK, Wolfe RA, Leichtman AB, et al. (2003) Chronic rena failure after transplantation of a nonrenal organ. N Engl J Med 349: 931-940.
35. Lyu DM, Zamora MR (2009) Medical complications of lung transplantation. Proc Am Thorac Soc 6: 101-107.

36. Mateen FJ, Dierkhising RA, Rabinstein AA, van de Beek D, Wijdicks EF (2010) Neurological complications following adult lung transplantation. Am J Transplant 10: 908-914.

37. Goldstein LS, Haug MT 3rd, Perl J 2nd, Perl MK, Maurer JR, et al. (1998) Central nervous system complications after lung transplantation. J Heart Lung Transplant 17: 185-191.

38. Moffatt-Bruce SD, Pesavento T, Von Viger J, Nunley D, Pope-Harman A, et al. (2008) Successful management of immunosuppression in a patient with severe hyperammonemia after lung transplantation. J Heart Lung Transplant 27: 801803.

39. Lichtenstein GR, Yang YX, Nunes FA, Lewis JD, Tuchman M, et al. (2000) Fatal hyperammonemia after orthotopic lung transplantation. Ann Intern Med 132: 283-287.

40. Hinchey J, Chaves C, Appignani B, Breen J, Pao L, et al. (1996) A reversible posterior leukoencephalopathy syndrome. N Engl J Med 334: 494-500.

41. Hosenpud JD, Bennett LE, Keck BM, Edwards EB, Novick RJ (1998) Effect of diagnosis on survival benefit of lung transplantation for end-stage lung disease. Lancet 351: 24-27.

42. Thabut G, Christie JD, Ravaud P, Castier Y, Brugière O, et al. (2008) Survival after bilateral versus single lung transplantation for patients with chronic obstructive pulmonary disease: a retrospective analysis of registry data. Lancet 371: 744-751.

43. Kugler C, Fischer S, Gottlieb J, Welte T, Simon A, et al. (2005) Health-related quality of life in two hundred-eighty lung transplant recipients. J Heart Lung Transplant 24: 2262-2268.

44. Ortega T, Deulofeu R, Salamero P, Roman A, Masnou N, et al. (2009) Healthrelated Quality of Life before and after a solid organ transplantation (kidney, liver, and lung) of four Catalonia hospitals. Transplant Proc 41: 2265-2267.

45. Santana MJ, Feeny D, Jackson K, Weinkauf J, Lien D (2009) Improvement in health-related quality of life after lung transplantation. Can Respir J 16: 153 158

46. Smeritschnig B, Jaksch P, Kocher A, Seebacher G, Aigner C, et al. (2005) Quality of life after lung transplantation: a cross-sectional study. J Heart Lung Transplant 24: 474-480. 